\title{
ANÁLISE DA QUALIDADE DE VIDA NO TRABALHO: UMA AVALIAÇÃO ERGONÔMICA EM CARÁTER PÓS OCUPAÇÃO DE UMA COPIADORA E ENCADERNADORA
}

\author{
OLIVEIRA, Gabriella Kurtz (1); \\ BINS ELY, Vera Helena Moro (2) \\ (1) FATENP, Mestre \\ e-mail:gabikurtz.arquitetura@gmail.com \\ (2) UFSC, Doutora \\ e-mail:vera.binsely@gmail.com
}

\begin{abstract}
RESUMO
Em ambientes comerciais é comum o empreendedor deslocar a atenção e os investimentos financeiros para à satisfação e conforto dos clientes, deixando de lado os "bastidores" do negócio. Portanto, o objetivo desta pesquisa é avaliar a qualidade ambiental de uma copiadora e encadernadora, focada nos funcionários, a fim de alertar a importância de um espaço agradável para a saúde e melhora de produtividade da equipe. De caráter investigativo e qualitativo, a pesquisa utiliza multimétodos da área de arquitetura e ergonomia. Os resultados relacionam o espaço físico com os usuários, traduzindo os principais constrangimentos encontrados e propondo diretrizes para adequações espaciais.
\end{abstract}

Palavras chave: Avaliação pós-ocupação; ergonomia; psicologia ambiental.

\section{ABSTRACT}

At commercial environments, the owners usually focus their attention and financial resources for satisfying the customers, putting aside "the backstage of the business". Given that, the purpose of this research is the evaluation of the environmental quality of a copier and binder, focused on employees, considering the importance of creating also a pleasant space for workers, preserving their health and improving productivity. With an investigative and qualitative character, the research adopts multimethods of the area of architecture and ergonomics. The results encompass the relationship of physical space and users, exposing several conflicts that may be developed for guidelines and project proposals in future projects or space adaptations.

Keywords: Post-occupancy evaluation; ergonomics; environmental psychology.

\section{INTRODUÇÃO}

Inúmeros autores da área da ergonomia conceituam-na como uma ciência e tecnologia de projeto que tem como objetivo a melhor adequação dos objetos e meio ambiente aos usuários, englobando questões de segurança, conforto, bem-estar e eficácia no uso. Segundo lida (2005), a expansão do estudo da ergonomia ocupou principalmente setores de serviços e trabalhos domésticos, não abordando apenas situações que exigem esforço 


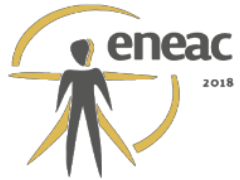

físico, mas principalmente englobando aspectos cognitivos, ou seja, de aquisição e processamento de informações.

Seguindo esta área do setor de serviços, esta pesquisa aborda uma avaliação ambiental pós ocupação, imergindo em aspectos de ergonomia e psicologia ambiental. Para isso, e de acordo com Oliveira e Mont'Alvão (2015), a Ergonomia possui diversos métodos já aplicados como processo de investigação sobre um ambiente construído, dentre eles o Método de Análise Ergonômica do Ambiente Construído (MEAC). Este é um dos instrumentos mais recentes no leque de opções existentes e foi o escolhido para aplicação neste trabalho. Sua importância e grande diferencial está na subdivisão do estudo em duas etapas, uma investigação de ordem física e outra de ordem cognitiva.

A primeira responde pelas análises físicas do ambiente composto por três etapas: análise global do espaço, identificação da configuração ambiental e avaliação do ambiente em uso durante o desenvolvimento das atividades. A segunda investigação, responde pelas avaliações de percepção do usuário com o ambiente. Por fim, o diagnóstico de conflitos e proposições de melhorias resumem e concluem a pesquisa.

\section{OBJETIVO}

Apresentar a avaliação ergonômica pós ocupação de uma empresa que oferece serviços de copiadora e encadernadora, identificando possíveis problemas ergonômicos ou de conforto ambiental existentes no espaço e associados a percepção dos profissionais do local, a fim de propor recomendações que contribuam para melhor qualidade de vida dos trabalhadores e melhora no rendimento e qualidade serviço prestado.

\section{METODOLOGIA}

Enquadrada em uma pesquisa do tipo multidisciplinar, descritiva na sua primeira etapa e qualitativa de caráter exploratório, além das revisões bibliográficas sobre o tema e caracterização da profissão de operador de máquina copiadora, segundo a Classificação Brasileira de Ocupações - $\mathrm{CBO}$, a pesquisa utiliza de métodos pertencentes às investigações abordadas na Análise Ergonômica do Ambiente Construído (MEAC), das quais constituem dois blocos a serem apresentados neste trabalho, são eles:

- Análise ergonômica do sistema Homem-Tarefa-Ambiente: Para este, Moraes e Mont'Alvão (2003) afirma que o início deste processo de análise compreende a identificação da situação "problema" do sistema, ou seja, momento em que são determinados os constrangimentos para o usuário em uma análise apenas do espaço. Neste caso, os métodos utilizados compreendem registros fotográficos, levantamento dimensional do espaço e do mobiliário, e análise por observação direta e mapeamento comportamental pelo pesquisador (Zeisel (2006) e Rheingantz (2009)).

Concomitantemente foi realizada a aplicação de uma entrevista semiestruturada e um questionário nórdico com a proprietária e os funcionários da empresa.

Colhidas essas informações, foi realizada a transcrição de informações antropométricas e ergonômicas dos usuários e ambiente, com auxílio do software AutoCad, com a posterior intenção de realizar simulações de percentis extremos dos funcionários da amostra com relação a possíveis constrangimentos posturais e de movimentação para realização das tarefas diárias do trabalho.

- Percepção Ambiental do Usuário: Neste caso, procura-se identificar a percepção que o usuário tem em relação ao espaço em que trabalha. De acordo com Vasconcelos, 


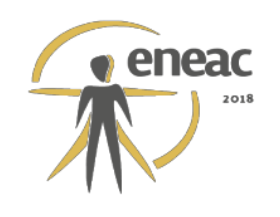

Villarouco, Soares (2010) é o momento de realizar uma análise que vai além das características físicas do ambiente, envolvendo também o comportamento, sensações, necessidades e desejos de quem utiliza do local, que é de fato, o elemento que sofre mais perto o impacto das sensações que o ambiente pode transmitir. Os autores assim, indicam ser possível trabalhar neste campo da percepção e cognição utilizando mapas mentais, observação de traços físicos, questionários e constelação de atributos.

Por fim, com base nos materiais confeccionados e obtidos in loco, foi possível o desenvolvimento de sugestões de melhora das condições ergonômicas que podem refletir positivamente na qualidade de vida e de trabalho dos envolvidos.

\section{ANÁLISE DE RESULTADOS}

Os dados coletados durante os métodos já citados serão apresentados focados nos constrangimentos principais encontrados e relatados pelos usuários da empresa.

\subsection{Análise Ergonômica do Sistema Homem-Tarefa-Ambiente}

Neste bloco, se inicia a identificação da situação "problema" referente ao ambiente físico e a relação existente com seu usuário direto, portanto, procura-se levantar a maior quantidade de informação possível sobre a situação, de forma a permitir a definição clara sobre o trabalhador, a tarefa (prescrita e real) e o ambiente (empresa).

\subsubsection{Caracterização Empresarial e Física do Ambiente}

A empresa de fotocópias e encadernação, fundada em 2001, localiza-se, desde sua inauguração, na mesma edificação próxima a um campus da Universidade Federal de Santa Catarina em Florianópolis, SC. Com uma configuração de equipe familiar de três pessoas, o período de atendimento oficial segue os padrões do comércio local, de segunda a sextafeira, podendo acontecer dias esporádicos de horas extras de funcionamento. Independente do dia, os turnos de trabalho acontecem por meio de revezamento dos funcionários (proprietária e familiares) pelo fato de não ter fechamento no período do almoço, sendo este inclusive, o horário de maior movimento de clientes.

As atividades exercidas e oferecidas na empresa são: cópias simples e impressões de documentos, cópias de materiais didáticos (livros e afins), encadernações em espiral e brochura, elaboração de material gráfico simples (capas, agendas, cartazes e banners), plotagem de material técnico (folhas de tamanho A2, A1 e A0), formatação de trabalhos acadêmicos e venda de materiais escolares.

A empresa possui área útil de 41,21 $\mathrm{m}^{2}$, desse total, 3,02 $\mathrm{m}^{2}$ são destinados ao banheiro de uso dos funcionários. É importante citar que a empresa está incorporada em uma edificação que possui mais salas comerciais ocupadas ao lado, dentre essas está instalado um bar com funcionamento inicial em torno das $17 \mathrm{~h} 30 \mathrm{~min}$. A Figura 1 abaixo apresenta o objeto de estudo e sua inserção no contexto urbano. 


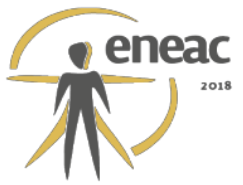

Figura 1. Caracterização do local e inserção no contexto urbano.

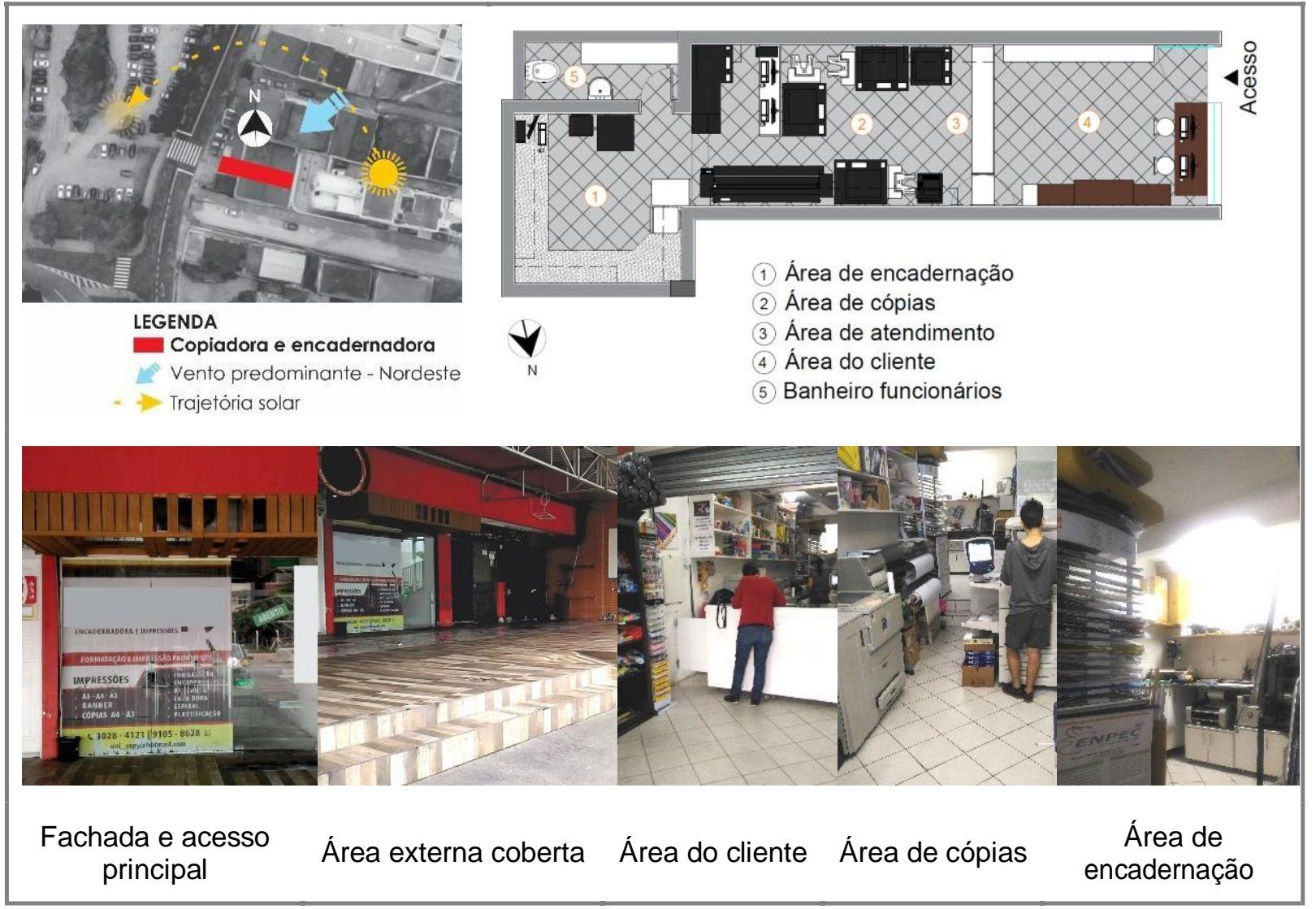

Fonte: Elaborado pela autora, 2017.

Em análise à Figura 01, a configuração interna espacial, na planta baixa apresentada acima, é possível claramente identificar uma geometria linear com acesso apenas pela fachada principal, totalmente envidraçada (Foto 1). A área destinada aos clientes (identificada em planta baixa pelo $\left.n^{\circ} 4\right)$, e a área central ( $n^{\circ} 2$ e 3) e posterior da empresa ( $n^{\circ}$ 1), que são ocupadas apenas pelos funcionários, são ambientes com revestimentos claros, iluminados artificialmente e sem ventilação natural.

Ainda com relação a itens físicos do ambiente, de acordo com Villarouco e Mont'Alvão ((2011) apud Oliveira e Mont'Alvão (2015)) dentre os elementos que compõe o ambiente e que devem ser considerados em uma análise ergonômica, estão aqueles referentes ao conforto ambiental (lumínico, térmico e acústico). Assim, esta etapa foi realizada na pesquisa por meio de equipamentos devidamente calibrados e com medições de acordo com normativas técnicas.

A Tabela 1, evidencia apenas os níveis de iluminação, por se destacar como situação problema, e está separada pelas áreas apresentadas na planta baixa da Figura 1 , descrevendo os dados coletados, os quais possuem na coluna ao lado um comparativo com base na Norma Técnica vigente, ou seja, NBR 5413 (1992) para iluminação média necessária na área de trabalho de acordo com o uso. 
Tabela 1. Índices de conforto ambiental lumínico.

\begin{tabular}{|lcc|c|}
\hline \multicolumn{4}{c}{ ILUMINAÇÃO (lux) } \\
\hline LOCAL DE MEDIÇÃO & $\begin{array}{c}\text { Turno } \\
\text { MANHÃ }\end{array}$ & $\begin{array}{c}\text { Turno } \\
\text { TARDE }\end{array}$ & Normas Técnicas \\
\hline ÁREA DE ENCADERNAÇÃO (1) & 105 & 98 & NBR 5413 \\
ÁREA DE CÓPIAS (2) & 187 & 169 & $200-300-500$ \\
ÁREA CLIENTES (4) & 215 & 307 & $300-500-750$ \\
\hline
\end{tabular}

Fonte: Elaborado pela autora, 2017.

Tanto pelos valores obtidos referentes à iluminação quanto pela sensação in loco, é evidente os níveis baixos de iluminamento. Em todas as áreas da empresa há a utilização de lâmpadas fluorescentes tubulares, porém em quantidade reduzida ao que seria o ideal além dos agravantes causados pela existência de muitas vigas estruturais altas, que acabam por gerar sombreamento em alguns locais. Não há entrada de iluminação natural significativa nas medições, sendo esta perceptível apenas na área de clientes.

Quanto ao ruído, não foram identificados nem relatados, problemas significantes. Neste item podem ser englobados apenas ruídos provenientes das máquinas copiadoras, iluminação e ar condicionado, estando todos os níveis acústicos de acordo com o exigido pelas normas técnicas NBR 10152 (2017) e NR17 (2007). Ruídos externos não geram incômodo visto que a fachada de acesso é recuada e distante da via.

O nível de temperatura e umidade relativa do ar, por razões do ambiente funcionar sempre com os condicionadores de ar ligados e estes terem controle de temperatura pelo usuário, as condições de conforto térmico foram consideradas de acordo com a NR 17 (2007), que estipula valores entre $20^{\circ}$ e $23^{\circ} \mathrm{C}$.

\subsubsection{Caracterização dos usuários e das tarefas}

Através de entrevistas e considerando apenas os funcionários fixos da empresa, totalizando três pessoas, a Tabela 2 apresenta as caraterísticas físicas, de rotina e a carga horária de trabalho realizada por cada pessoa na empresa.

Tabela 2. Caracterização dos usuários.

\begin{tabular}{|c|c|c|c|c|c|c|c|c|}
\hline & 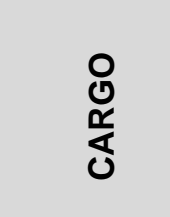 & 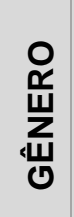 & 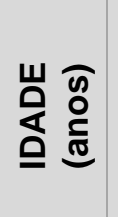 & 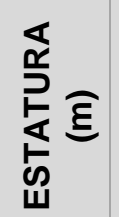 & ㅇ⿺ㄴ & 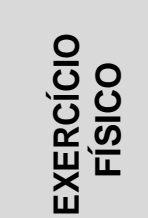 & 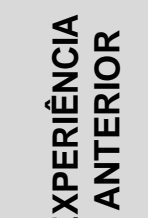 & 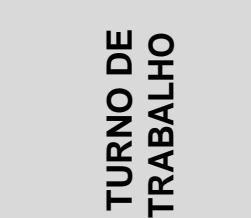 \\
\hline F1 & Func. & $\mathbf{F}$ & 36 & 1,70 & Destro & Não & Não & $08: 00-17: 00$ \\
\hline F2 $^{*}$ & Propriet. & $\mathbf{F}$ & 33 & 1,61 & Destro & Não & $\begin{array}{l}\text { Sim, } 11 \\
\text { anos }\end{array}$ & $11: 30-19: 30$ \\
\hline F3 & Propriet. & M & 37 & 1,69 & Canhoto & $\begin{array}{c}\text { Sim, } \\
1 \times / \text { sem. }\end{array}$ & $\begin{array}{c}\text { Sim, } 20 \\
\text { anos }\end{array}$ & $11: 30-19: 30$ \\
\hline
\end{tabular}

${ }^{*}$ Realiza atividades externas (administrativas) da copiadora no turno da manhã.

Fonte: Elaborado pela autora, 2017. 
Com relação às tarefas realizadas, estas, segundo lida (2005), são um conjunto de objetivos prescritos, que os trabalhadores devem cumprir, contida em documentos formais, como a descrição de cargos. Porém há diferença entre o que é prescrito e a atividade que é executada na realidade. Isto acontece, pois, esta última se refere ao comportamento do trabalhador, na realização de uma tarefa, ou seja, o que se passa efetivamente no escritório, ao longo dos dias, nas condições locais, ambientais, operacionais e organizacionais. (MORAES; MONT'ALVÃO, 2003). A Tabela 3 apresenta as tarefas realizadas pelos funcionários da copiadora e obtidas através de entrevista e observação realizada em visita exploratória. Estas tarefas foram pareadas quanto às atividades prescritas pela Classificação Brasileira de Ocupações, concluindo que os trabalhos desenvolvidos na empresa estão todos de acordo com a CBO.

Tabela 3. Relação de tarefas e rotinas de atividades por funcionários (em destaque as atividades comuns a todos).

\begin{tabular}{|ll|}
\hline \multicolumn{4}{|c|}{ TAREFAS E ROTINAS - OBSERVADAS E RELATADAS } \\
\hline F1 & $\begin{array}{l}\text { Atendimento ao público; Cópias e impressões; Encadernações em espiral; } \\
\text { Encadernações em brochura; Cortes na guilhotina; A partir das 16h30min - capas } \\
\text { (encadernações). }\end{array}$ \\
\hline F2 & $\begin{array}{l}\text { Gerência (externa à copiadora); Ajustes de formatação de trabalhos acadêmicos; } \\
\text { Atendimento ao público; Cópias e impressões; Encadernações em espiral. }\end{array}$ \\
\hline F3 & Atendimento ao público; Cópias e impressões; Encadernações em espiral. \\
\hline
\end{tabular}

Fonte: Elaborado pela autora, 2017.

Após esta análise das tarefas é possível apresentar o resultado do questionário nórdico aplicado com os trabalhadores, desenvolvido com a intenção de avaliar as condições de saúde física no que tange aspectos osteomusculares dos usuários em relação à sua atividade exercida. A Tabela 4 evidencia as dores relatadas por cada funcionário. Em geral, as queixas e ocorrências estão concentradas na região das costas e pernas.

Os acidentes são citados e podem ter sido ocasionados, segundo relato dos funcionários, devido à falta de espaço físico no local, pequena circulação e pouca iluminação, e em alguns casos, apenas por desatenção. Parte destas justificativas são apresentadas no estudo antropométrico desta pesquisa, descritos no item a seguir.

Tabela 4. Resultado simplificado do Questionário Nórdico.

\begin{tabular}{cc|c|c}
\hline & F 1 & F 2 & F 3 \\
\hline Gênero & F & F & M \\
\hline Estatura $(m)$ & 1,70 & 1,61 & 1,69 \\
\hline Dificuldade ou desconforto & & & Falta espaço \\
\hline Vontade de se sentar & sim & não & não \\
\hline Já ocorreu acidente & Corte e queima & Corte e queda & \\
\hline Problema em alguma região & $\begin{array}{c}\text { Quadril, coxas e } \\
\text { joelho }\end{array}$ & Tornozelo e pés & Dorsal e lombar \\
\hline \multicolumn{4}{c}{ LEGENDA: } \\
\hline NAO POSSUI & POSSUI & SEM DOR & COM DOR \\
\hline
\end{tabular}

Fonte: Elaborado pela autora, 2017. 


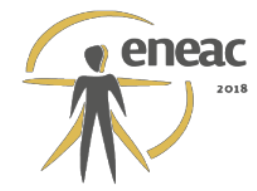

Conforme observação in loco e entrevista, a funcionária ( $\mathrm{F} 1)$ permanece em pé durante maior parte da jornada de trabalho, sentando uma média de duas vezes durante 0 expediente, apenas. É compatível seu relato de sentir dores no quadril e pernas nos últimos 7 dias e durante os últimos 12 meses, além de expressar vontade de se sentar mais vezes, se possível. O funcionário (F3) relatou em entrevista sentar-se em média 5 vezes durante a jornada de trabalho, estando satisfeito com a frequência, porém também relatou dores importantes, como dorsal e lombar nos últimos 12 meses. Estes problemas relatados pelos funcionários $(\mathrm{F} 1)$ e $(\mathrm{F} 3)$ tendem a estar vinculados a má postura do trabalhador junto a seu equipamento de trabalho e mobiliário, possível de ser verificado em itens posteriores do trabalho. A funcionária (F2) é a que trabalha maior parte do tempo sentada, relatou dores apenas nos pés nos últimos 7 dias e nos últimos 12 meses.

\subsubsection{Análise Antropométrica do espaço (circulação, postos de trabalho, leiaute e mobiliário)}

Toda a análise antropométrica entre homem e ambiente no contexto da rotina de trabalho, foi realizada através de simulação computacional gráfica que avalia, com auxílio de manequins, as posturas e alcances adotados durante o exercício das funções no dia-a-dia do expediente. Neste caso, considerando o fato da empresa funcionar com uma equipe familiar, e por este motivo, ter uma rotatividade de funcionários nula, adotou-se como medidas de modelo os percentis extremos da amostra: para mulher 1,61 $\mathrm{m}$ de altura e para homem $1,69 \mathrm{~m}$.

A circulação, tópico de grande reclamação de $100 \%$ dos usuários, em um espaço de trabalho deve ser adequada a fim de evitar interrupções das atividades realizadas pelas pessoas desse ambiente e possíveis acidentes durante passagens, seja devido ao mobiliário ou utilização dos equipamentos e materiais. A Figura 2 a seguir, apresenta os conflitos identificados na circulação e utilização dos espaços pelos funcionários.

De acordo com lida (2005), o espaço de trabalho é um volume imaginário, necessário para o organismo realizar os movimentos requeridos durante o trabalho. Neste caso, um posto de trabalho apertado, com restrição de espaço, além de exigir movimentos mais precisos, tendem a causar estresse, redução da velocidade de trabalho e aumento de erros.

Figura 2. Conflitos de circulação.

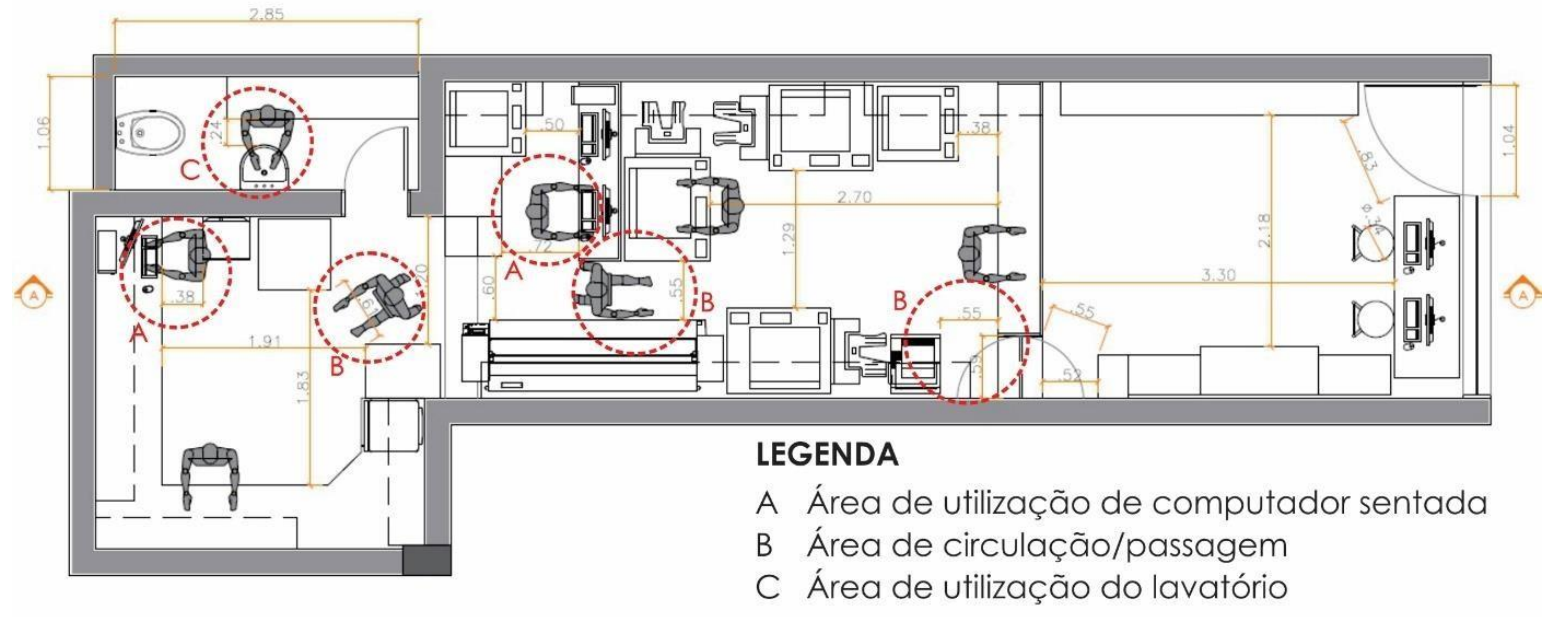



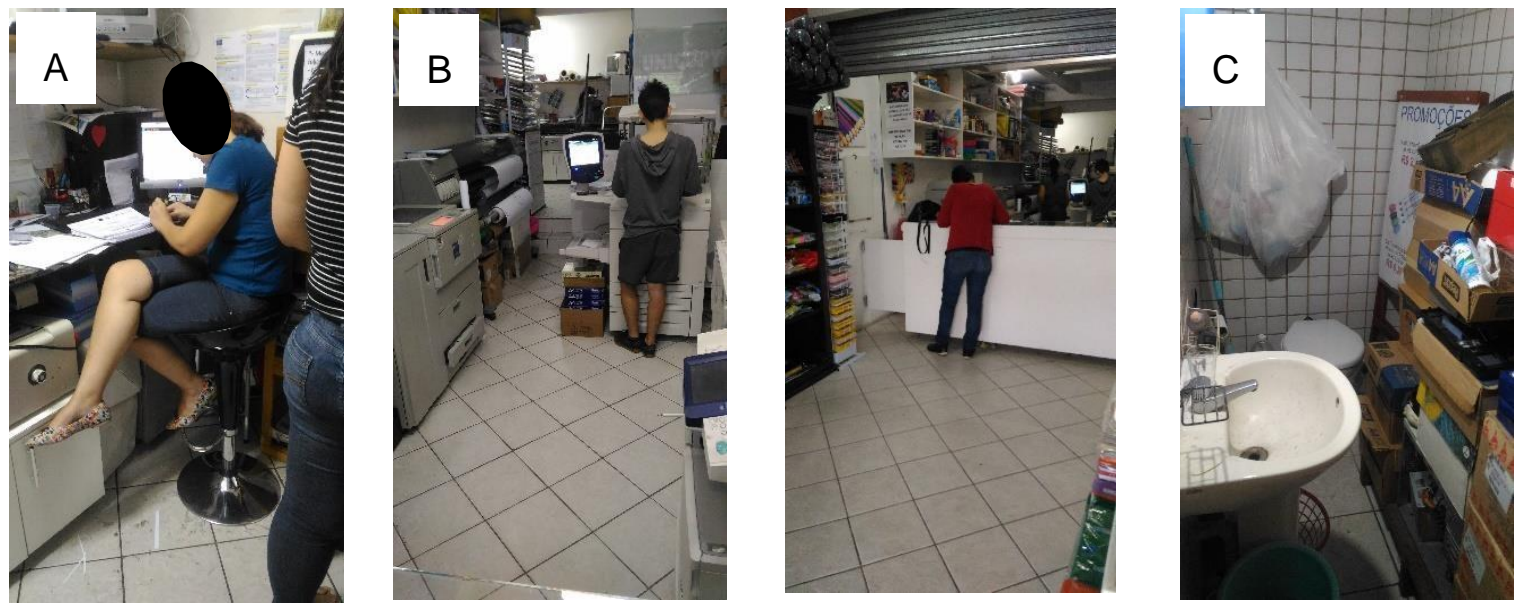

Fonte: Elaborado pela autora, 2017.

Ainda segundo lida (2005), quando o corredor possui dimensão menor que $60 \mathrm{~cm}$ de largura, a probabilidade de erros (esbarrões em equipamentos) é superior a $80 \%$. Aumentando-se a largura, a partir de $64 \mathrm{~cm}$, as pessoas conseguem andar normalmente, sem forçar movimentos corporais. Traduzindo em medidas mais específicas para situações de comércio, segundo Panero e Zelnik (2010), as circulações representadas na Figura 2 pela letra (B) deveriam possuir entre $76,2 \mathrm{~cm}$ e $91,4 \mathrm{~cm}$, enquanto que no projeto variam entre $55 \mathrm{~cm}$ e $61 \mathrm{~cm}$, em desacordo com ambos autores. Já a área de circulação para uso de computador sentado deve medir entre $50,8 \mathrm{~cm}$ e $61 \mathrm{~cm}$, e a área de utilização de lavatório deve ser de no mínimo 45,7 cm. No projeto, essas dimensões são entre $38 \mathrm{~cm}$ e 50 $\mathrm{cm}$ para o primeiro caso e de $24 \mathrm{~cm}$ no segundo.

A Figura 3 identifica os fluxos que ocorrem no ambiente pelos funcionários da copiadora em grande parte do horário de funcionamento. A observação totalizou 3 horas e aconteceu no intervalo em que todos os funcionários estão presentes no ambiente, portanto, entre as 14:00 e às 17:00 horas. É evidente a existência de conflito de fluxos na área de cópias. Essa aglomeração em momentos de maior movimento de clientes piora, pois todos ficam realizando atendimento no balcão e utilizando as máquinas, visto ser a atividade de maior procura na empresa.

Figura 3. Mapeamento de fluxos.

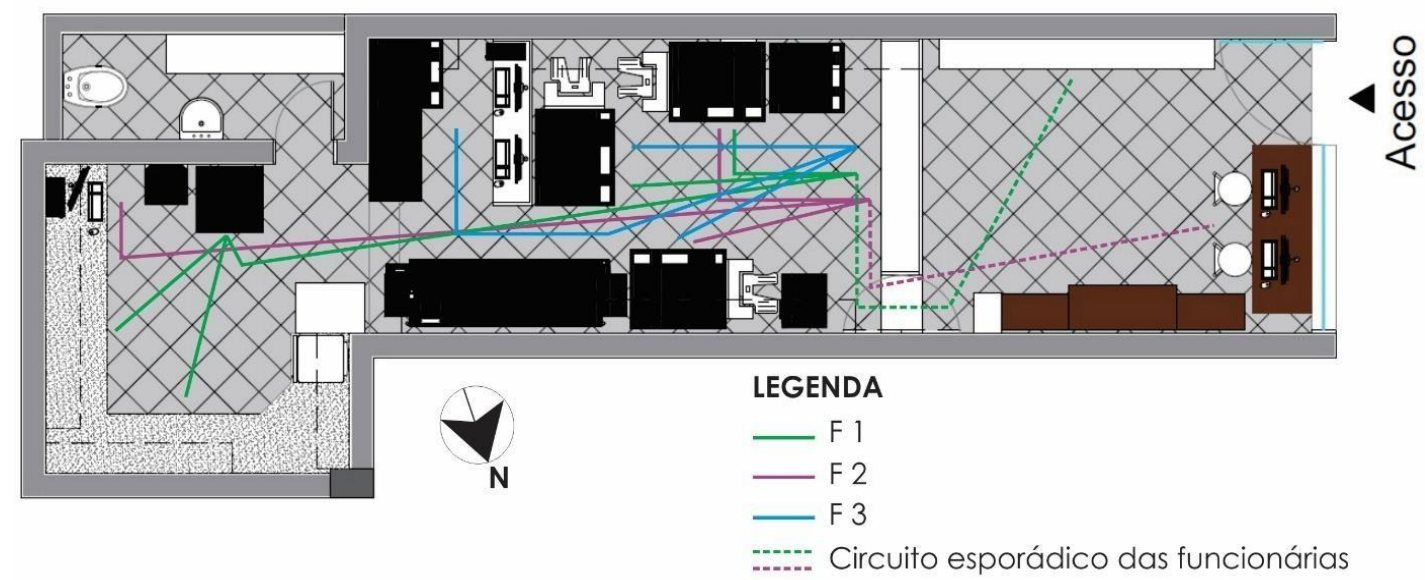

Fonte: Elaborado pela autora, 2017. 


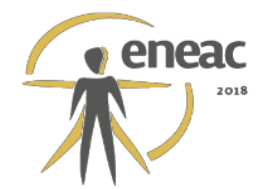

Além deste cenário, há em alguns momentos, a necessidade de se receber produtos dos fornecedores e também de acesso de clientes para utilização dos computadores - quando os frontais estão ocupados - localizados ao fundo da área de cópias. Com trajeto semelhante ao dos funcionários, essas situações tendem a agravar os conflitos no local, causando perda na produtividade e rendimento, além de poder gerar stress físico e mental nos envolvidos, justificando parte dos acidentes narrados pelos funcionários.

Nada diferente de como é a circulação e os espaços em planta baixa, as alturas traduzidas pelos cortes representados na Figura 4, também apresentam com clareza problemas ergonômicos entre os percentis máximo e mínimo estudados, e o mobiliário existente na copiadora.

Figura 4. Análise ergonômica dos conflitos quanto ao uso de mobiliários.

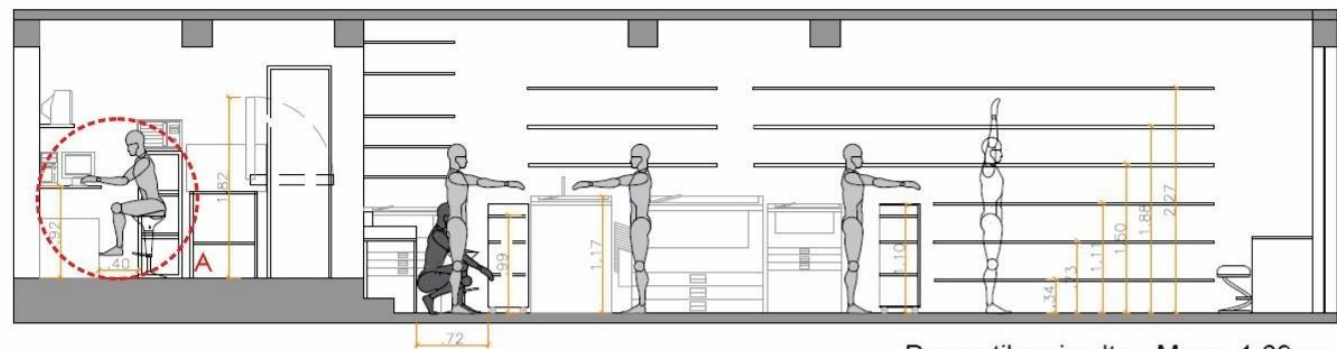

Percentil mais alto - Masc. $1.69 \mathrm{~m}$

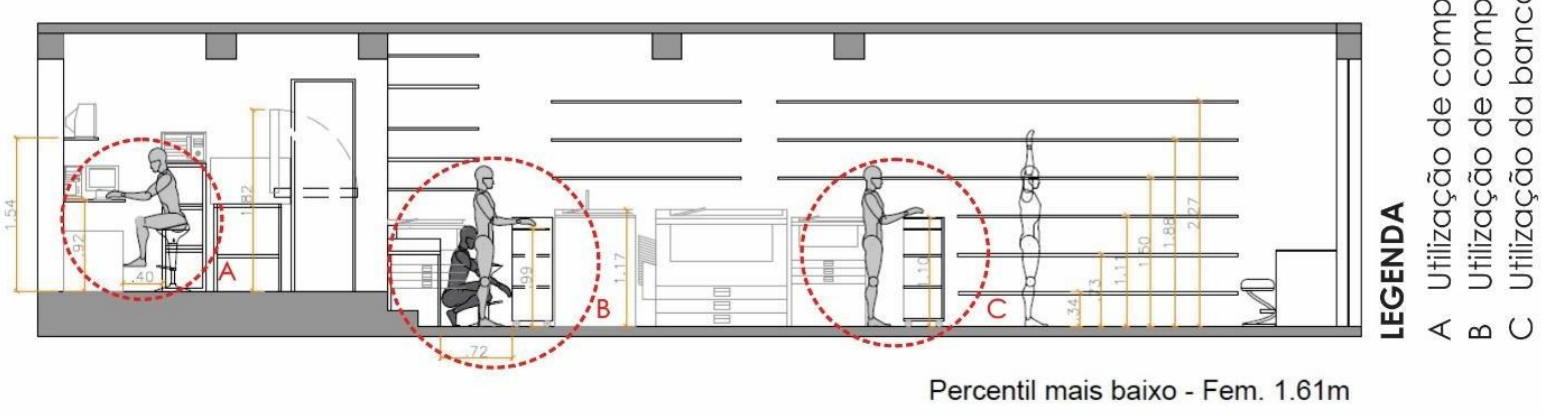

Fonte: Elaborado pela autora, 2017.

Conforme orientação de lida (2005) e Panero e Zelnik (2010), a qualidade da interface entre estação de trabalho e usuário é determinante no grau de conforto e bem-estar do grupo de funcionários e na eficiência de produção dentro daquele espaço. No que tange o uso de computador, os autores, para uso sentado, indicam uma altura de bancada entre $73,7 \mathrm{~cm} \mathrm{e}$ $76,2 \mathrm{~cm}$, além de espaço para as pernas abaixo do tampo da mesa, possibilitando uma postura com angulações das pernas e dos troncos adequadas, além de apoio para os pés. Para uso em pé, a altura da bancada deve estar entre 101,6 e 106,7 cm, para angulação ideal dos braços e consequente liberação de esforço extra para a coluna. Nessas situações, respectivamente, no caso estudado as alturas da bancada estão de $92 \mathrm{~cm}$ (para uso sentado) e $99 \mathrm{~cm}$ (para uso em pé), portanto, ambos em desacordo com o que é considerado ideal.

A bancada de atendimento ao público, que também é utilizado como mostruário também está em desacordo possuindo $110 \mathrm{~cm}$ de altura enquanto que o ideal seria de, no máximo, $96,5 \mathrm{~cm}$ segundo Panero e Zelnik (2010). Já as prateleiras de exposição de produtos estão instaladas a diferentes alturas, gerando desconforto para ambos sexos apenas nos dois níveis superiores (188 cm e $227 \mathrm{~cm}$ de altura em relação ao piso) no que tange o alcance dos trabalhadores. As prateleiras localizadas na área de cópias tendem a gerar maior 


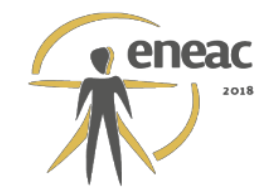

dificuldade de acesso visto os obstáculos com maior profundidade (máquinas) abaixo das mesmas. Nestes casos, é utilizada uma pequena escada de quatro degraus para alcance dos materiais.

\subsection{Percepção Ambiental do Usuário}

Nesta etapa são apresentados os resultados dos métodos abordados na percepção e comportamento dos usuários, ou seja, entrevistas, poema dos desejos e observação de traços físicos, voltados apenas às questões "problemas" encontradas na pesquisa.

As entrevistas, realizadas com os funcionários, foram previamente elaboradas a fim de coletar informações que auxiliassem a transcrever fatores subjetivos dos usuários em relação a fatores objetivos do ambiente adquiridos in loco. As respostas obtidas estão transcritas na Tabela 5, e por fim, um poema dos desejos com a frase: "Eu gostaria que esta copiadora fosse ou tivesse...", é relatado na Tabela 6.

Dentre os fatores de projeto é unânime as reclamações e descontentamento a respeito dos fluxos (espaço de circulação). Curiosamente, apesar das reclamações de circulação e dos problemas de ergonomia encontrados nos móveis, a distribuição e dimensões dos mobiliários são considerados bons pelos entrevistados. No âmbito dos fatores ambientais, a iluminação natural e artificial foram os únicos a receberem avaliações negativas. Resultado coerente com o que foi verificado através de equipamentos e já comentado no item 4.1.1 desta pesquisa.

Tabela 5. Síntese das respostas da entrevista.

\begin{tabular}{|c|c|c|c|c|c|}
\hline & & & F 1 & F 2 & F 3 \\
\hline \multirow{3}{*}{$\begin{array}{l}\text { FATORES DE } \\
\text { PROJETO }\end{array}$} & \multirow{3}{*}{ FUNC } & Distribuição Layout & REGULAR & RUIM & BOM \\
\hline & & $\begin{array}{l}\text { Dimensões } \\
\text { Mobiliário }\end{array}$ & BOM & PÉSSIMO & BOM \\
\hline & & $\begin{array}{c}\text { Fluxos/Larguras } \\
\text { mínimas }\end{array}$ & RUIM & RUIM & RUIM \\
\hline \multirow{4}{*}{$\begin{array}{c}\text { FATORES } \\
\text { AMBIENTAIS }\end{array}$} & \multirow{2}{*}{ ILUM. } & Natural & REGULAR & PÉSSIMO & PÉSSIMO \\
\hline & & Artificial & RUIM & REGULAR & RUIM \\
\hline & & Temperatura & ÓTIMO & RUIM & ÓTIMO \\
\hline & & Som & BOM & REGULAR & ÓTIMO \\
\hline $\begin{array}{l}\text { AVALIAÇÃO } \\
\text { PELOS } \\
\text { USUÁRIOS }\end{array}$ & & JROBLEMAS & $\begin{array}{l}\text { Bagunça } \\
\text { Circulação }\end{array}$ & $\begin{array}{l}\text { Bagunça } \\
\text { Circulação } \\
\text { Ergonomia } \\
\text { Iluminação }\end{array}$ & $\begin{array}{l}\text { Ergonomia } \\
\text { Circulação }\end{array}$ \\
\hline
\end{tabular}

Fonte: Elaborado pela autora, 2017.

Uma situação que mantém a problemática relacionada à falta de espaço, são os fatores sociais levantados na pesquisa, em que é relatado haver deficiência de espaço pessoal, ou seja, falta um espaço para guardar os pertences, espaço de descanso e também espaço para lanches rápidos, havendo descontentamento de como estes ocorrem, na mesma bancada de trabalho ao lado dos materiais de uso.

Quanto às avaliações pessoais, que foram respondidas de forma escrita pelos entrevistados, o maior descontentamento evidenciado é a bagunça, circulação deficiente e ergonomia do espaço. Este mesmo "espaço físico" aparece em todas as respostas ao 


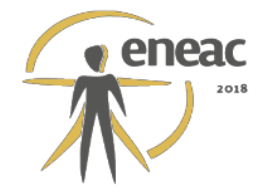

poema de desejos (Tabela 6), sendo fator relevante ao desempenho das tarefas com eficiência e segurança.

Tabela 6. Síntese de resultados do poema dos desejos (grifado a palavra-chave).

\begin{tabular}{cc}
\hline F 1 & DESEJOS \\
\hline F 2 & Mais espaço, apresentação melhor, móveis sob medida para ocupar menos \\
espaço e organização.
\end{tabular}

Além das entrevistas reveladas acima, foi realizado uma observação de traços físicos do ambiente onde o objetivo principal é detectar, segundo Zeisel (2006), manifestações de identidade, mensagens públicas, produtos do uso e adaptações de uso. Os principais traços identificados foram: desgastes em paredes e sujeira acumulada embaixo de maquinário, ambos passíveis de estar também a falta de espaço para realização de limpeza adequada e com fácil acesso.

\section{DIAGNÓSTICO E RECOMENDAÇÕES}

Os métodos escolhidos, por permitirem avaliar o ambiente de forma físico-espacial e através de questões de percepção ambiental, possibilitam a formação de um diagnóstico global, centrando as recomendações de melhoria focadas no trabalhador da empresa, conforme apresentado na Tabela 7 abaixo. Esta pesquisa, portando, vai ao encontro com objetivos da profissão de arquitetura e urbanismo, ou seja, criar, pensar, projetar e executar considerando o usuário dos espaços e equipamentos.

Tabela 7. Principais problemas identificados e recomendações.

\begin{tabular}{|ccc|}
\hline $\begin{array}{c}\text { PRINCIPAIS } \\
\text { CONFLITOS }\end{array}$ & MOTIVO & RECOMENDAÇÕES \\
\hline $\begin{array}{c}\text { Circulação e } \\
\text { fluxos }\end{array}$ & $\begin{array}{c}\text { Atividades } \mathrm{x} \\
\text { espaço físico }\end{array}$ & $\begin{array}{c}\text { Organizar o leiaute para adequar larguras de } \\
\text { passagens nos fluxos principais, prevendo a situação } \\
\text { mais crítica em número de funcionários }\end{array}$ \\
\cline { 2 - 3 } $\begin{array}{c}\text { Conforto } \\
\text { Ambiental }\end{array}$ & $\begin{array}{c}\text { Iluminação } \\
\text { natural e } \\
\text { artificial } \\
\text { insuficientes }\end{array}$ & $\begin{array}{c}\text { Realizar projeto e adequações específicas, criado por } \\
\text { um profissional habilitado para propor a lluminância } \\
\text { adequada para cada área. }\end{array}$ \\
\hline $\begin{array}{c}\text { Mobiliário e } \\
\text { equipamentos }\end{array}$ & $\begin{array}{c}\text { Ergonomia } \\
\text { deficiente }\end{array}$ & $\begin{array}{c}\text { Projeto de mobiliário adequado para cada situação de } \\
\text { uso (priorizando mobiliário sob medida para auxiliar } \\
\text { na ampliação do espaço de circulação) }\end{array}$ \\
\cline { 2 - 3 } & & $\begin{array}{c}\text { Organizar a utilização das prateleiras e armários } \\
\text { aéreos de diferentes alturas com materiais de maior } \\
\text { ou menor fluxo de venda/ utilização. }\end{array}$ \\
\hline
\end{tabular}

Fonte: Elaborado pela autora, 2017. 


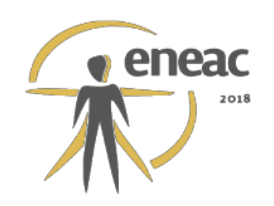

\section{CONCLUSÕES}

Com cada vez mais empresas iniciando atividades e cada vez mais trabalhadores e clientes informados e cientes da necessidade de cumprimento de determinadas normas técnicas, inclusive de segurança e bem-estar, a prática de estudos abordando o tema desta pesquisa se torna relevante, seja para empregador quanto para o trabalhador. Nesta pesquisa, o estudo de caso apresentado, realizou-se em uma copiadora e encadernadora da cidade de Florianópolis, tendo como foco principal o espaço existente em relação aos seus funcionários e o desempenho de suas atividades no local.

Utilizou-se de variados métodos vinculados tanto à ergonomia quanto à psicologia ambiental. Destes, há àqueles que possibilitaram por observação e pesquisa bibliográfica caracterizar o ambiente, usuários e estrutura/organização da empresa, e àqueles que técnica e analiticamente, como análise antropométrica, que realçaram e confirmaram situações conflitantes (subdimensionamento do espaço e circulações). Além de constatações feitas pelo pesquisador e dos resultados analíticos possibilitados pelos métodos, há também os questionários que apontam opiniões dos usuários quanto à ambiência do seu local de trabalho.

Com todos os resultados obtidos de cada método aplicado, compilados e entrelaçados foi possível conhecer detalhes da amostra escolhida para o trabalho, em seguida, com o diagnóstico dos principais problemas concluído, foram propostas recomendações, de diferentes escalas de intervenção, em um quadro resumo a fim de proporcionar maior qualidade de vida, segurança e conforto aos usuários.

Por fim, este artigo tem a intenção de colaborar com projetos e adequações para o setor de serviço estudado, ao mesmo tempo que tem como pretensão alertar para a importância de tratar o espaço dos funcionários do comércio de igual forma como é realizado para o cliente.

\section{REFERÊNCIAS BIBLIOGRÁFICAS}

ABNT, A. BRASILEIRA DE NORMAS TÉCNICAS. NBR 5413 - lluminância de interiores. Brasil. 1992.

ABNT, A. BRASILEIRA DE NORMAS TÉCNICAS. NBR 10152 - Níveis de pressão sonora em ambientes internos a edificações. Brasil, 2017.

IIDA, I. Ergonomia: projeto e produção. 2a edição ed. São Paulo: Blucher, 2005.

MINISTÉRIO DO TRABALHO. NR 17 - Ergonomia. Brasil, 2007.

MORAES, A. DE; MONT'ALVÃO, C. R. Ergonomia: conceitos e aplicações. Rio de Janeiro: iUsEr, 2003.

OLIVEIRA, G. R. DE; MONT'ALVÃO, C. R. Metodologias utilizadas nos estudos de Ergonomia do Ambiente Construído e uma proposta de modelagem para projetos de Design de Interiores. Estudos em Design. p. 150-165, 2015.

PANERO, J.; ZELNIK, M. Dimensionamento Humano para Espaços Interiores. 1a. 5a imp ed. Barcelona: Editorial Gustavo Gili, 2010.

RHEINGANTZ, P. A. et al. Observando a qualidade do lugar: procedimentos para avaliação pósocupação. Rio de Janeiro: Faculdade de Arquitetura e Urbanismo, Pós-Graduação em Arquitetura, 2009.

VASCONCElOS, C. F. E; VILlAROUCO, V.; SOARES, M. M. Contribuição da Psicologia Ambiental na Análise Ergonômica do Ambiente Construído. Ação ergonômica, v. 5, p. 14-20, 2010.

ZEISEL, J. Inquiry by design: environment/behavior/neuroscience in architecture, interiors, landscape, and planning. Revised Ed ed. New York: W. W. Norton \& Company, 2006. 